\title{
Nueva arquitectura espacial, pobreza urbana y desigualdad territorial
}

New Spatial Architecture, Urban Poverty and Territorial Inequality

\section{Alicia Ziccardi Contigiani*}

\section{RESUMEN}

Los principales problemas de las ciudades latinoamericanas son la pobreza y la desigualdad y por ello son temas de central importancia de la investigación social y de los estudios urbanos en particular. En este artículo se analiza la manera como se expresa en la actualidad la dimensión territorial de la pobreza y de la desigualdad, ya que estos procesos no sólo son la expresión espacial de procesos económicos y sociales, sino que las graves carencias y nuevas inequidades en el acceso y calidad de los bienes y servicios urbanos provoca una amplificación de las desigualdades estructurales.

Palabras clave: Pobreza urbana, desigualdad territorial, regiones metropolitanas.

\section{ABSTRACT}

The main problems of Latin American cities are poverty and inequality and therefore they constitute central issues of social research and urban studies. This article analyzes the way in which the territorial dimension of poverty and inequality is currently expressed, since these processes are not only the spatial expression of economic and social processes but also the serious deficiencies and new inequities in the access and quality of urban goods and services causes an amplification of structural inequalities.

Key Words: Urban poverty, territorial inequality, metropolitan regions.

Recibido el 20 de diciembre de 2018 y aprobado 17 de enero de 2019

* Investigadora del Instituto de Investigaciones Sociales de la Universidad Nacional Autónoma de México. Miembro del Sistema Nacional de Investigadores. ziccardi@ unam.mx 


\section{Introducción}

Los principales problemas de las ciudades latinoamericanas son la pobreza y la desigualdad y por ello uno de los principales temas de la investigación social y de los estudios urbanos. En este sentido, en las tres últimas décadas, cuando las ciudades se han transformado rápida y profundamente, ante la necesidad de refuncionalizar los espacios urbanos para adecuarlos a las exigencias de la economía global, estos procesos adquieren nuevas connotaciones y obligan a diseñar nuevas estrategias y herramientas de investigación.

En el caso de los estudios urbanos interesa analizar particularmente la manera como se expresa actualmente la dimensión territorial de la pobreza y de la desigualdad, ya que estos procesos no sólo son la expresión espacial de procesos económicos y sociales sino que las graves carencias y nuevas inequidades en el acceso y calidad de los bienes y servicios urbanos provoca una amplificación de las desigualdades estructurales.

En este trabajo el referente territorial son las grandes ciudades, en particular una de las megaciudades del mundo, la Ciudad de México, ciudad capital, espacio central que cumple con la principal función de articular la economía nacional a la globalización y que ha sido históricamente el principal escenario de la vida económica, social, cultural y política del país.

En sus rasgos más generales, la gran metrópoli se ha modificado en su ciudad central creándose auténticos nodos de modernidad que han cambiado el paisaje urbano al redensificarse algunas zonas centrales, consolidadas y habitadas por las clases medias; asimismo, estos procesos suelen estar atravesados por diferentes conflictos sociales. Pero el rasgo más distintivo y que interesa analizar en este trabajo es la dimensión territorial de la pobreza y la desigualdad, lo cual se inscribe en la creación de una periferia cada vez más lejana y paupérrima que modifica la morfología urbana de la gran ciudad, creándose una gran región urbana metropolitana, una mega-ciudad dispersa, con límites difusos entre su paisaje urbano y rural, con enclaves de riqueza y opulencia y desarrollos habitacionales con grandes carencias de bienes y servicios.

Las principales ideas de este trabajo se desarrollan en tres apartados. En el primero se hace un breve recuento sobre los conceptos que han aportado las 
ciencias sociales en América Latina sobre la pobreza urbana y la desigualdad territorial desde hace más de medio siglo. También se hace referencia a las relaciones que existen entre ambos conceptos, poniendo especial atención en dos procesos claves: la segregación residencial y la fragmentación urbana.

En segundo lugar, se analiza la nueva arquitectura espacial de la gran región urbana de la Ciudad de México. Finalmente, se exponen algunos fundamentos de las políticas sociales urbanas del gobierno de la Ciudad de México que incorporando una perspectiva de derechos intentan contrarrestar las grandes desigualdades territoriales de la ciudad capital, pero que no inciden en el ámbito de la gran región metropolitana. A ello se agregan algunas reflexiones finales.

\section{Periferias urbanas: pobreza urbana y desigualdad territorial}

Las periferias urbanas habitadas por los sectores populares han sido uno de los principales objetos de estudio de la sociología y la antropología urbanas de América Latina, desde la década de los años sesenta y setenta del siglo xx. Estos barrios populares fueron el observatorio privilegiado de los debates sobre la teoría de la marginalidad que protagonizaron inicialmente José Nun (1969) y Fernando Henrique Cardoso (197I) y al que se sumaron muchos otros científicos latinoamericanos. También desde la visión ecológica y psicosocial proveniente de la Escuela de Chicago, Gino Germani (I967), consideraba que la ciudad contrarrestaba la marginalidad porque constituía un mecanismo de inclusión social que permitía la integración geográfica de la sociedad y facilitaba la integración social vinculada a la participación y a la movilización. Pero además las periferias fueron el escenario de los trabajos sobre el potencial político de las clases populares, tanto del populismo de Gino Germani (1967, 1973) como del polémico concepto de cultura de la pobreza desarrollado por Oscar Lewis (196I).

Una década después, estos barrios y asentamientos populares y los llamados movimientos sociales urbanos fueron objeto de estudio de las pioneras investigaciones de Manuel Castells (1972, 1974), Jordi Borja (1975), Ernesto Pastrana y Joaquín Duque (1972); Luis Antonio Machado Da Silva y Alicia Ziccardi (I98I; Ziccardi (I977, I983, I984), sobre las callampas, villas miseria 
y favelas. A ello se sumaron los trabajos de Teolinda Bolívar y Alberto Lovera sobre la organización social de los pobladores de los ranchos venezolanos, los de Fernando y Diego Carrión sobre los barrios pobres de Quito, los de María Clara Echeverría sobre Medellín, los de Gilma Mosquera sobre Cali y Bogotá. En México destacan los de Enrique Ortiz, Gustavo Romero, Priscilla Connolly, René Coulomb, Alejandro Suárez Pareyón y Arturo Mier y Terán, desarrollados desde copevi y Cenvi, los de Martha Schteingart en el colmex, los de Emilio Pradilla, Armando Cisneros, Jorge Legorreta, Roberto Ebeinshutz, Pedro Moctezuma y Bernardo Navarro en la UAM y de Manuel Perlo y Alicia Ziccardi en el ins-unam. ${ }^{1}$

Lo más importante de estos destacados núcleos de académicos latinoamericanos fue no sólo dejar valiosos testimonios de las condiciones de vida de los sectores populares sino también de las condiciones de pobreza y de grandes desigualdades que existían en nuestras ciudades, otorgando particular atención a los nuevos actores que irrumpían en la vida urbana, los movimientos sociales transformadores de la ciudad que enarbolaban junto a sus demandas de vivienda y bienes y servicios la democratización de la vida política.

Asimismo, se destaca que la ciudad era un espacio que proporcionaba mecanismos de integración social, principalmente a quienes migraban del medio rural y lograban acceder a un trabajo remunerado, a la educación, la salud, los bienes culturales, la movilidad, etcétera. Cabe señalar que dado su bajo nivel de calificación, la mayoría sólo lograba incorporarse de manera informal al mercado de trabajo percibiendo bajas remuneraciones, sin acceder a la seguridad social y soportando precarias condiciones habitacionales en barrios populares periféricos.

Han pasado varias décadas y aunque muchos de aquellos barrios originales se han consolidado y han mejorado sus condiciones de vida, en la actualidad han proliferado en la periferia cada vez más lejana diferentes tipos de asentamientos aislados, que contrastan con la opulencia de los barrios cerrados de clases altas. Es precisamente esta realidad urbana la que

I Para una revisión de los trabajos de las y los académicos mexicanos y latinoamericanos, durante la década de los ańos ochenta del siglo xx, véase Ziccardi, Alicia (1989), De la ecología urbana al poder local, en Revista Mexicana de Sociología, año LI, núm. 1, enero-marzo. 1989. México, Instituto de Investigaciones Sociales (IIS), UnAm, pp. 129-149. 
se confronta diariamente e indica que se asiste a una ampliación de las desigualdades territoriales.

Pero lo importante para las clases populares es acceder a la ciudad, esa aglomeración de población, actividades, mercado y bienes y servicios colectivos para el conjunto de la ciudadanía con independencia de la capacidad de apropiación que tengan los individuos en el mercado (Lojkine, Castells). Además, la ciudad es el espacio en que se pueden obtener más fácilmente las capacidades que requieren los individuos para su funcionamiento económico, social, político (educación, salud), para expresarlo en términos de Amartya Sen (200I).

Ahora bien, si la ciudad es un bien que posee un alto valor social y colectivo, es a la vez un espacio que excluye, segmenta, segrega a los que menos tienen y es generador de profundas desigualdades. Por ello en ańos recientes algunos estudiosos de las ciudades de la región consideran que los fuertes cambios que se advierten en la morfología del espacio urbano -los cuales dejarán la huella de esta época de la sociedad de la información- son producto de una combinatoria de factores endógenos - estructurales, culturales e históricos- y factores exógenos, propios de un mundo globalizado (Castells, 20I2; De Mattos, 200I; Borja, 2005; Ziccardi, 2008b).

Así, se advierten un conjunto de factores que tienden a homogeneizar el paisaje urbano con sus nuevas formas de organizar la producción y el consumo de bienes urbanos o artefactos arquitectónicos, construidos con originales diseños que forman parte de los nuevos centros de negocios y que constituyen formas de apropiación privada, o de asociaciones público-privadas en el espacio público (Cuenya, 20I2). Pero al mismo tiempo, en la era de la desigualdad existe en las ciudades un alto porcentaje de la población viviendo en condiciones de pobreza urbana (Reygadas y Ziccardi, 20Io).

Estos fenómenos obligan a distinguir, a precisar y a hallar las interrelaciones que existen conceptualmente entre la desigualdad y la pobreza, considerando a este último fenómeno como complejo y multidimensional, de escasez de recursos sociales, culturales, institucionales, territoriales y políticos que afecta particularmente a los sectores de menores ingresos (Ziccardi, 2008c). Una pobreza que está asociada, principalmente pero no exclusivamente, a las condiciones de inserción que prevalecen en el mercado de trabajo: inestabilidad, informalidad, bajos salarios, precariedad laboral 
y desempleo. Una pobreza urbana que Townsend (1970) caracterizó como pobreza relativa, la cual debe medirse en función del nivel de vida histórico y socialmente aceptado en una sociedad y en una ciudad, es decir se es pobre no sólo a partir de considerar los ingresos.

Para participar en el mercado y en la sociedad, particularmente en la sociedad urbana, no sólo se requiere un mínimo de recursos económicos que cubran las necesidades alimentarias sino que se requiere garantizar un conjunto de capacidades (educación y salud) y particularmente se debe acceder a bienes patrimoniales, en particular a una vivienda, así como a espacios públicos, medios de movilidad, transporte y recreación, porque también, en palabras de Sen (200I), el acceso a estos bienes dependerá de que el trabajador y su familia puedan funcionar, transitar y pertenecer a la sociedad en la que viven.

La desigualdad, en cambio, es un concepto relacional, que remite a las diferencias y a la dispersión de la distribución del ingreso y de los recursos en una sociedad pero es claro que la desigualdad está fuertemente relacionada con la pobreza. En un trabajo anterior y siguiendo una idea de Ugo Pipitone (2003) sobre las grandes transformaciones que se observan en contextos modernizadores, señalamos que no existe una tendencia única en relación con la desigualdad en las ciudades y que esto se puede corroborar particularmente en el caso de la Ciudad de México, donde se registran procesos alentadores propios de una ciudad de derechos (Reygadas y Ziccardi, 20IO). Precisamente, la ciudad posee un robusto marco legal y desde 2017 su Constitución, que establecen las bases para diseñar y aplicar políticas públicas innovadoras que permitan alcanzar mayores condiciones de igualdad o equidad social, otorgando visibilidad y atención a las demandas de los pueblos indígenas; empoderando a las mujeres para que puedan decidir libremente ante la difícil decisión de interrumpir un embarazo, reconociendo las necesidades de personas con capacidades diferentes y las reivindicaciones de los jóvenes para acceder a espacios para la cultura y la recreación, una ciudad capital que ha creado un original e innovador programa para atender las necesidades básicas de los adultos mayores y que promueve proyectos ciudadanos para crear y/o mejorar los espacios públicos que estimulen la vida social y la solidaridad ciudadana (Ziccardi, 2008b).

Pero al mismo tiempo existen nuevas dinámicas económicas y sociales que mantienen o agravan las antiguas desigualdades, que se entrelazan en- 
tre sí y son fuente de inaceptables procesos de exclusión social, tales como las diferentes formas de precarización del trabajo urbano, la aparición de nuevas prácticas discriminatorias hacia los jóvenes de las clases populares, procesos económicos y sociales vinculados a la economía del delito, lo cual contribuye al incremento de la violencia y la inseguridad. Asimismo, se pone de manifiesto la fragilidad de una democracia local que avanza lentamente en la construcción de una dinámica social capaz de neutralizar la actual polarización social.

\section{Nueva arquitectura espacial, segregación social y fragmen- tación urbana}

En un difícil contexto en el que son fácilmente observables las condiciones de pobreza y las marcadas desigualdades estructurales, se advierten un conjunto de inequidades territoriales que las acrecientan aún más. En gran medida éstas surgen de la nueva arquitectura espacial de las grandes regiones urbanas, la cual se expresa en una particular y extendida forma urbana, diferente a las tradicionales zonas metropolitanas de la ciudad manufacturera como lo ha dejado claro Manuel Castells (2012). Se trata de una estructura urbana policéntrica con jerarquías distintas entre los centros y subcentros, donde las actividades tienden a estar desconcentradas y los servicios están diseminados en un amplio territorio. Asimismo, Castells pone particular énfasis en la existencia de redes globales que conectan tanto las regiones metropolitanas más importantes como sus zonas de influencia.

Otro rasgo de esta nueva forma urbana es que la frontera entre lo urbano y lo rural es difusa y que se acelera la conversión de usos rurales a urbanos, lo cual coincide con los procesos de desindustrialización y terciarización de la economía, prevaleciendo las funciones del sector servicios, tal como lo estudió profundamente Gustavo Garza (2012) para el caso de la Ciudad de México. Pero por un lado, es claro el impulso que tienen un conjunto de actividades vinculadas a los servicios avanzados, propios de la sociedad de la información (los servicios financieros, la banca, los seguros, las TICs), y en nuestras ciudades se advierte la expansión de un terciario de muy baja productividad y alto grado de informalidad, que se expresa particularmente 
en el comercio popular de calle, que es la actividad predominante de los sectores populares que carecen de calificación. Estos procesos ponen en tensión el derecho al trabajo y el derecho a la ciudad, los cuales confrontan permanentemente el ejercicio de la autoridad local con los liderazgos populares legitimados por garantizar no sólo el desarrollo de una actividad remunerada sino el acceso a bienes como la salud y la satisfacción de las necesidades sociales básicas. Esto se ha constatado en nuestros estudios sobre el papel de las mujeres lideresas del comercio popular de las calles en el Centro Histórico de la Ciudad de México (Ziccardi, coord., 20Io).

También se advierte el pasaje de una urbanización de base urbana a una urbanización de "'base regional', la cual promueve nuevas formas de centralidad urbana caracterizadas por la fragmentación y el policentrismo" (Aguilar, 2004 y Aguilar y Lozano, 2012).

Para la investigación urbana uno de los principales desafíos, como lo señala Dematteis (1998), es conocer las formas de articulación de la estructura urbana consolidada con nodos de la nueva centralidad (los centros y subcentros) que constituyen el espacio de referencia para la construcción de la identidad local. En este sentido, Francois Ascher (2004) observó que existe una constelación de ciudades pequeñas o nodos cada vez más distantes de los centros urbanos, lo que da lugar a una forma urbana que denominó metápolis, caracterizada por presentar espacios extensos, discontinuos, heterogéneos y multipolarizados.

Tanto Oriol Nel-lo (1998) como Manuel Castells, (2012) se han encargado de vincular esta expansión territorial, productora de grandes desigualdades en la calidad de vida que ofrece la gran ciudad, al reclamo de mejores medios de comunicación y transporte público que desincentiven el modelo ciudad del automóvil y que acorten las distancias entre los nuevos nodos de actividad y el espacio que habita la población ya que de alguna manera deben estar integrados física, territorial y funcionalmente.

Todas estas transformaciones han dado lugar a diferentes calificativos para describir las ciudades del siglo xxI como ciudades difusas, dispersas, meta ciudades, para describir estas grandes regiones metropolitanas, como una nueva forma urbana con la que se ha inaugurado en la práctica el "urbanismo de la movilidad", un urbanismo que lleva a privilegiar la construcción de grandes obras viales, vías rápidas o segundos pisos, que faciliten la movi- 
lidad a través del automóvil privado, un bien que sólo poseen los sectores de ingresos medios o altos. Pero ello no es suficiente, se requieren grandes inversiones en medios de transporte masivos como los trenes rápidos interurbanos, metrobús, trenes rápidos, que conecten la ciudad periférica con la ciudad central y garanticen la movilidad de los sectores populares. Pero además estos procesos están asociados al debilitamiento de las políticas de desarrollo urbano y de la acción institucional, y de las regulaciones sobre los usos del suelo, un proceso de deslegitimación la planeación territorial, que abona a los intensos procesos urbanos y sociales de segregación residencial y fragmentación urbana.

Sabatini, F. Cáceres González y Cerda, J. (200I) definen los procesos de segregación social en el espacio urbano como la aglomeración de familias de una misma condición social en el espacio, más allá de cómo sean definidas las diferencias sociales. Identifican dos dimensiones objetivas de la segregación: por un lado, el grado de concentración espacial de los grupos sociales y por otro, la homogeneidad social que presentan las diferentes áreas internas de las ciudades.

En este sentido, la segregación residencial de los sectores populares se funda principalmente en la búsqueda de suelo barato en el cual autoproducir precarias viviendas. Pero también se advierte un proceso de autosegregación de los sectores de altos ingresos que eligen vivir en los llamados "barrios cerrados", buscando no sólo una vivienda y equipamientos de calidad, sino seguridad, un medio ambiente apropiado y el valor simbólico de estar entre iguales que comparten códigos de socialización y de vida. Es decir, se trata de un espacio cerrado a los de afuera (Ziccardi, 2008a).

Asimismo, desde una perspectiva más sociológica Emilio Duhau y Ángela Giglia (2008) incorporaron la noción de "división social del espacio residencial” de la aglomeración urbana”. Esta idea se vincula con el hecho de que "la desigualdad urbana no se puede entender sólo a partir de las áreas residenciales fijas, sino que se debe ampliar la mirada hacia las 'lógicas de circulación', tomando en cuenta las prácticas cotidianas y sus distintas esferas y espacios de intercambio e interacción" (Jirón, 20IO: IO4, cit. en Segura, 2015: 74).

Lo importante es que se pueden identificar territorios segregados residencialmente donde sus habitantes logran una inserción económica, en 
contrapartida en una zona central pueden vivir trabajadores y trabajadoras que no logran insertarse plenamente en una actividad económica, social y cultural. Es decir, analíticamente se trata de dos lógicas diferentes, una económica y otra espacial o territorial y ambas con dinámicas diferentes. Sin embargo, Kaztman (20II) trata de hallar sus vínculos y señala que la segregación residencial, la segmentación laboral y la segmentación educativa pueden potenciarse mutuamente, generándose un proceso de "aislamiento social y progresivo de los pobres urbanos". Inclusive advierte que este proceso se ve agravado por la deserción de las clases medias en los espacios públicos, donde antes se generaban procesos de socialización educativa y cultural compartidos.

Ahora bien, otra perspectiva de análisis son los procesos de exclusión social que identificó Robert Castel (1995) y que hacen referencia a las prácticas discriminatorias de las que son objeto principalmente las clases populares. En particular se ha detectado que los habitantes de ciertas zonas geográficas que viven en los barrios pobres, experimentan estigmas por sus características étnicas, culturales o religiosas y suelen ser discriminados en el trabajo, en el acceso al crédito y a la vivienda, además que con frecuencia se los asocia a la inestabilidad política y al crimen, procesos que han sido denominados por Bird como las "trampas de la pobreza" (cit Ziccardi, 2008a).

Finalmente, es importante incorporar la idea de fragmentación urbana, una noción que alude a la existencia de límites físicos, es decir, se trata de una "segregación acentuada que se inscribe en el espacio a través de barreras" (Tullier, 2005, cit. en Segura, 2015: 75). La fragmentación urbana remite a "la materialidad y a la forma del espacio, donde se distingue entre lo abierto y lo cerrado, entre lo continuo y discontinuo, y sobre todo al impacto que esto tiene en las relaciones sociales” (Segura, 20I5: 75). Así, para Daniel Kosak (2009) son "los límites duros, lo confinado y los obstáculos, un estado espacial de separación que a menudo es acompańado de divisiones socio-económicas y/o étnicas dominadas por el principio de la exclusión y donde hay una reducción en el número de lugares de encuentro universal".

Estos procesos económicos, sociales y urbanos actúan en interdependencia pero no son necesariamente irreversibles, sino que la inversión pública, las normas urbanísticas, las decisiones del gobierno local pueden contribuir a lograr sociedades y territorios urbanos que favorezcan que la ciudad actúe 
como un mecanismo de integración social (Germani, 1967). En este sentido, para contrarrestar las grandes desigualdades territoriales, así como la segregación y la fragmentación urbana, David Harvey (2013) señala la necesidad de que se transfieran las plusvalías generadas en los cambios de uso del suelo hacia aquellas zonas degradadas o más pobres de la ciudad.

Se trata entonces de reconocer la legitimidad de las reivindicaciones y demandas de los llamados nuevos movimientos sociales urbanos que han surgido en diferentes ciudades del mundo reclamando mayor justicia espacial y el derecho a la ciudad. Como es sabido, esta noción del derecho a la ciudad fue acuñada por Henri Lefebvre (1978) poniendo énfasis en su capacidad para generar un proceso transformador con sentido ciudadano que se oponga a la segregación urbana y la precariedad de las condiciones de vida que ofrecía la periferia urbana parisina a la clase obrera, en la segunda mitad del siglo xx. Pero actualmente, la idea del derecho a la ciudad ha sido resignificada, principalmente por el geógrafo marxista David Harvey, quien ha destacado que no es el legado intelectual de Lefebvre sino el resultado de lo que ha venido sucediendo en las calles y barrios de muchas ciudades en el mundo en años recientes "como un grito de socorro de gente oprimida en tiempos desesperados" (Harvey, 20I3). Es un derecho colectivo para configurar la ciudad de acuerdo con las necesidades y deseos de quienes las habitan, pero más allá del acceso individual a los recursos que la ciudad almacena o protege, este derecho hoy lo ostenta una pequeña élite política y económica. Por ello, la única manera de lograr su pleno ejercicio es exigir un control democrático sobre la producción y uso del excedente de capital que se genera en la ciudad (Harvey, 2013).

\section{I. La región metropolitana de la Ciudad de México: pobreza, desigualdad y nueva arquitectura espacial}

La Ciudad de México es un interesante laboratorio para analizar los procesos descritos en la principal ciudad del sistema urbano nacional. ${ }^{2}$ En este

\footnotetext{
${ }^{2}$ Este análisis se basa en los datos del Programa de Ordenamiento de la Zona Metropolitana del Valle de México (pozmvm), Programa Universitario de Estudios sobre la Ciudad
} 
sentido, se trata de una de las megaciudades del mundo que en 20 Io registraba más 2I millones de habitantes distribuidos de manera concentrada y la vez dispersa en I6 demarcaciones, actualmente denominadas alcaldías de la Ciudad de México, 59 municipios conurbados del Estado de México y 2I municipios del estado de Hidalgo. ${ }^{3}$ La expansión de la periferia entre 2000 y $20 I 0$ se da en la segunda corona del arco norte, en un territorio ya bastante lejano de la ciudad central, particularmente en los municipios de Acolman, Tecámac, Tizayuca, Huehuetoca; Chicoloapan del Estado de México, y en el estado de Hidalgo, Mineral de Reforma, principalmente lo largo de las carreteras México-Hidalgo, México-Toluca y México-Puebla y de las vías férreas. También los municipios habitados por los sectores populares como Ecatepec, Valle de Chalco e Ixtapaluca se han consolidado.

Al respecto Adrián Guillermo Aguilar (2002) ha afirmado acertadamente que en "los intersticios de este patrón surge una mezcla de usos del suelo en una región expandida, donde la agricultura tradicional se puede encontrar al lado de nuevos proyectos de vivienda urbana, parques industriales, desarrollos corporativos, sitios de recreación y toda clase de desarrollos suburbanos".

Un dato que da cuenta del intenso crecimiento urbano y de la aparición de una nueva arquitectura espacial dispersa es que en cuarenta años, la población en la Zona Metropolitana del Valle de México (ZMVM) se incrementó en sólo $\mathrm{I} .42$ veces, mientras que su superficie urbana lo hizo 3.57 veces. (CONAPO, 2OI2a, 2OI2b).

No obstante, la dispersión territorial tiene como contrapartida: i) la redensificación de ciertas zonas de la ciudad central; ii) la sobrevivencia de núcleos poblacionales tradicionales de origen étnico-cultural, los pueblos indígenas; iii) la creación de nuevos centros y subcentros de actividades económicas y iv) la concentración de viviendas de muy baja densidad, producto de la política habitacional del estado y de la acción de fraccionadores privados.

Pero uno de los principales rasgos de esta nueva morfología urbana son las grandes desigualdades territoriales -en términos de acceso y calidad inequitativo de los bienes de la ciudad- las cuales acrecientan las desigualdades

de la UnAm (2012).

${ }^{3}$ El 53\% de la población vive en los municipios conurbados del Estado de México, el $42 \%$ en el Distrito Federal y $5 \%$ en los municipios del estado de Hidalgo. 
socio-económicas o estructurales. En este sentido la desigualdad económica de la ZMVM, estimada a través del comportamiento del ingreso y medido éste por el Índice de Gini, indica que entre 1990 y 2010 presentó una moderada disminución, al igual que en otras ciudades de América Latina. Pero hay municipios que registran los más altos ingresos, localizados en nororiente, que son los que presentan la mayor desigualdad, como es el caso de Huixquilucan en el Estado de México y la alcaldía de Cuajimalpa en la Ciudad de México, donde se localiza la zona de Santa Fe rodeada de colonias populares de la ciudad. En el interior de estos espacios coexisten condiciones de vida precarias para los sectores populares (viviendas deterioradas, sin acceso o acceso a servicios de mala calidad) con auténticos enclaves de riqueza y opulencia habitados por clases altas, lo cual amplifica las desigualdades socio-económicas que existen entre estos habitantes.

Otro rasgo del patrón de urbanización de esta gran región es el intenso proceso de urbanización de la pobreza que la caracteriza (Ziccardi, 2008c). Según datos del conapo de 20io, casi la mitad (48\%) de las localidades de la ZMVM presentaban alto y muy alto grados de marginación. Por lo general son localidades ubicadas cerca de las áreas de conservación, en las que se mezclan actividades rurales y urbanas, las alcaldías de Milpa Alta, Tláhuac, Xochimilco y Tlalpan y los municipios del Estado de México localizados en las cercanías de las áreas de conservación de la Sierra Nevada y de la Sierra de las Cruces. Las localidades en muy alta marginación se localizan en 2I municipios del oriente y poniente del Estado de México, aunque se advierte que todo este extenso territorio está salpicado de bolsones con alto grado de marginación.

Los datos de CONEval sobre la medición multidimensional de la pobreza (20Io) complementan esta imagen e indican: i) la proporción de población en condición de pobreza es de 34.7I\%, es decir, poco más de 7 millones de personas; ii) las carencias en la calidad y espacios de la vivienda afectan a poco más de 2 millones de habitantes (aproximadamente IO\% del total) ${ }^{4}$;

${ }^{4}$ La población en situación de carencia por calidad y espacios de la vivienda se refiere a las personas que residen en viviendas que presentan, al menos, una de las siguientes características: I. El material de los pisos de la vivienda es de tierra. 2. El material del techo de la vivienda es de lámina de cartón o desechos. 3. El material de los muros de la vivienda es de embarro o bajareque; de carrizo, bambú o palma; de lámina de cartón, metálica o 
iii) Entre los municipios que más concentran estas carencias se encuentran los del suroriente del Estado de México: Amecameca, Atlautla y Ecatzingo; en el oriente Valle de Chalco Solidaridad y Chimalhuacán y en el norte, el municipio de Nextlalpan; iv) las carencias de servicios básicos de la vivienda afectan a un porcentaje de la población menor al 7.I8\% que corresponde a un millón y medio de habitantes ${ }^{5}$ y se concentra principalmente al suroriente del Estado de México, en el municipio de Ecatzingo y al poniente, en Villa del Carbón (puec, pomzvm, 20I2).

Otro dato importante sobre las causas que han generado este patrón de ocupación disperso y difuso de la ZMVM son los cambios introducidos desde el año 2000 en la política de vivienda, que han llevado a producir y financiar a través de los fondos habitacionales de los trabajadores (INFONAVIT, FOVISSTE) una masiva producción de vivienda sin crear ciudad y generando procesos de segregación residencial y fragmentación urbana (Ziccardi, 20I5 y 20I8a). En esta nueva realidad urbana, los desarrollos habitacionales han sido uno de los principales motores del crecimiento poblacional disperso y de baja densidad, con viviendas de calidad y tamańo diversos de acuerdo con el sector social al que atienden y a las características del mercado en el que se ofertan: público, privado, social.

Si bien por un lado, en la ciudad central se observa una importante oferta inmobiliaria de vivienda de calidad dirigida a los sectores medios y medios altos, las periferias urbanas, en cambio, se han reconfigurado a partir de la construcción de enclaves exclusivos para las clases altas y la masiva producción de vivienda social para sectores de ingresos medios y bajos. En este sentido, en 2010 en la ZMVM y de acuerdo con el censo existían 6 millones 500 mil viviendas, de las cuales más de una cuarta parte (26\%) se construyó entre los años 2005 y 20IO. De estas viviendas poco más de la mitad se produjo

asbesto; o material de desecho.4. La razón de personas por cuarto (hacinamiento) es mayor que 2.5 (CONEVAL, 2OIO).

5Se entiende por carencias en servicios básicos cuando el agua se obtiene de un pozo, río, lago, arroyo, pipa; o bien, si el agua entubada se adquiere por acarreo de otra vivienda, o de la llave pública o hidrante. Asimismo, si no se cuenta con servicio de drenaje, o el desagüe tiene conexión a una tubería que va a dar aun río, lago, mar, barranca o grieta. También si no se dispone de energía eléctrica y si el combustible que se usa para cocinar o calentar los alimentos es leña o carbón sin chimenea (CONEvAL, 20IO). 
en los municipios metropolitanos del Estado de México, principalmente en Tecámac, Huehuetoca y Zumpango.

Se trata de macro-conjuntos habitacionales de viviendas unifamiliares, de baja densidad cuya localización exige perder muchas horas y cubrir altos gastos en transporte para los desplazamientos. Además requieren de obras de urbanización que deben ser asumidas por los gobiernos locales sin garantizar que tengan las capacidades institucionales y financieras para hacerlo. Estos procesos generan segregación residencial en el espacio urbano y enclaves de viviendas que en poco estimulan la convivencia ciudadana y la cohesión social. Frente a ello una de las principales respuestas de los sectores populares ha sido el abandono de cientos de miles de viviendas e Inclusive se ha observado que para no continuar pagando su vivienda, abandonan su trabajo y vuelven a enfrentar la penuria de encontrar un lugar donde vivir.

De acuerdo con las estimaciones de INEGi (20IO), en el área del Valle de México, el I2\% del total de viviendas están desocupadas. La mayor parte, el $58 \%$, se localiza en los municipios del Estado de México, entre los que destacan Huehuetoca (45\%), Zumpango (40\%), Nextlalpan (26\%) y Tecámac $(20 \%)$ que son en los que más vivienda nueva financiada por los organismos se ha producido. En números absolutos se estima que existen 403 mil $97 \mathrm{I}$ viviendas deshabitadas en el Estado de México, mientras que en Hidalgo existen 78 mil 959 deshabitadas por los mismos motivos (PUEC, POZMVM, 20I2) (mapa I). Esto sin duda confronta el "éxito" proclamado en los discursos cuando se evalúan los resultados de la política de vivienda. Actualmente los organismos de vivienda han diseñado programas de recuperación de este parque habitacional pero no se garantiza que se mejore la calidad de las viviendas ni el acceso al transporte público (Ziccardi, 2015).

Pero lo importante es saber cuál es la opinión de quienes han adquirido una vivienda de interés social por la que pagarán durante décadas un crédito. La Encuesta Nacional sobre las Condiciones de Habitabilidad de la Vivienda, realizada por el Instituto de Investigaciones Jurídicas de la UNAM en 20I5, indica que al preguntarse a los entrevistados ¿cuál es el principal problema de las viviendas de interés social que construye el gobierno? en la ZMVM afirman que las viviendas adquiridas son muy pequeñas (38.3\%), de mala calidad y mal construidas (19.5\%) y que su ubicación es lejana (7.5\%); sin embargo, y a diferencia de las respuestas dadas por los habitantes de otras regiones, 


\section{Mapa I. Viviendas deshabitadas}

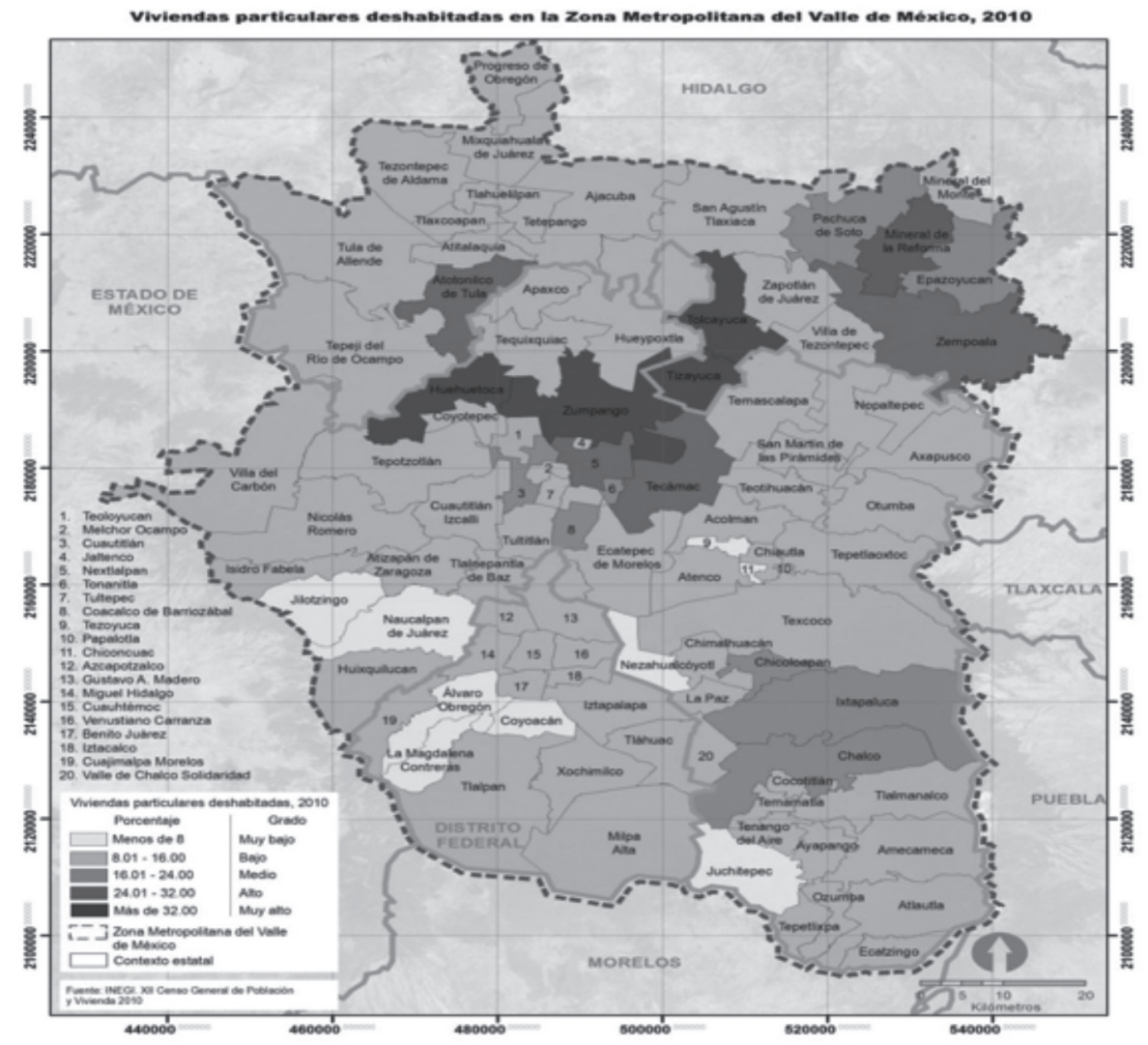


poco menos de una quinta parte (I8.7\%) de los entrevistados considera de que son caras (cuadro I $)^{6}$.

Cuadro I. Percepciones sobre los problemas de vivienda social

\begin{tabular}{|c|c|c|c|c|}
\hline Regiones & Centro & ZMVM & Norte & Sur \\
\hline Son muy pequeñas & 37.I & 38.3 & 28.2 & 25.4 \\
\hline Son muy caras & 32.9 & 18.7 & 22 & I8.I \\
\hline Mal construidas, de mala calidad & $15 \cdot 3$ & 19.5 & 19 & 37.8 \\
\hline Los materiales son de mala calidad & 5.8 & 9 & 8.5 & 15.5 \\
\hline $\begin{array}{l}\text { Los fraccionamientos están muy } \\
\text { retirados }\end{array}$ & 5.7 & 7.5 & IO. 3 & 6.3 \\
\hline Los malos servicios que tienen & 2.5 & 3 & 5.5 & 3.2 \\
\hline Otras (menciones dispersas) & I8.5 & 15.9 & I7.I & II.6 \\
\hline NS & $3 \mathrm{I}$ & 23.2 & 39.7 & $33 \cdot 3$ \\
\hline
\end{tabular}

Conviene terminar este apartado señalando que estos procesos de expansión territorial, incremento de las desigualdades territoriales, urbanización de la pobreza, segregación residencial y fragmentación urbana son también una consecuencia del debilitamiento de los procesos de planeación urbana y de la política de desarrollo urbano, así como de la muy compleja gobernanza multinivel que existe en la gran región urbana de la Ciudad de México y que presenta grandes limitaciones para lograr una gestión urbana eficiente y democrática.

${ }^{6}$ Para este análisis, véase Ziccardi, Alicia, (2015) Como viven los mexicanos. Análisis regional de las condiciones de habitabilidad de la vivienda, México: ilj, Dirección de Fomento Editorial, UNAM. 


\section{Ideas finales}

Enfrentar los problemas socio-económicos y urbanos que presentan las grandes regiones metropolitanas exige revisar y modificar las políticas económicas neoliberales y el conjunto de las políticas públicas que se subordinan a aquellas. Pero además este análisis debe considerar que en estos extensos y complejos territorios coexisten de manera conflictiva diferentes patrones de gobernanza, entre los cuales los más importantes son el asociativo y el colaborativo (Ziccardi, 20I8b).

Ante ello las llamadas políticas sociales urbanas (Bodemer, Coraggio, y Ziccardi, 1999) adquieren centralidad dado que su principal objetivo debe ser crear condiciones de equidad social, promoviendo y garantizando el ejercicio de los derechos de los ciudadanos (DESCA). Se trata de que la acción gubernamental recupere su misión original de garantizar al conjunto de la ciudadanía el acceso a bienes y servicios básicos que son derechos consagrados en caso de México en la Constitución de la República (artículos $3^{\circ}$ y $4^{\circ}$ ), en la Ley General de Vivienda, en ley de Asentamientos Humanos, Ordenamiento Territorial y Desarrollo Urbano y en diferentes documentos internacionales de los que México ha sido signatario. De igual forma, en la capital de la República, cuyo territorio forma parte de la la gran región de la Zmvm, rige la Carta de Derechos contenidos en la Constitución de la Ciudad de México, aprobada en 20I7, y un robusto marco legal que reconoce ampliamente los derechos ciudadanos (Ziccardi, 2018 a y b).

Es decir, existe actualmente un nuevo marco legal que rige para el conjunto de las ciudades mexicanas y en especial para la gran región metropolitana del Valle de México lo cual requiere revisar: i) la actuación de las instituciones del gobierno federal que inciden en los procesos de apropiación y uso del suelo y que inciden en el mercado habitacional y en el suministro de los servicios urbanos; ii) la institucionalidad particular de los gobiernos subnacionales de las entidades que actúan en la gran región metropolitana del valle de México - la Ciudad de México, el Estado de México y el de Hidalgo- y iii) el diseño y acción pública de los gobiernos locales, los municipios de los estados de México e Hidalgo y las alcaldías de la Ciudad de México.

Pero además deberá considerarse que el principal componente de toda esta nueva legislación es el reconocimiento del Derecho a la Ciudad. Hacer 
efectivo el mismo implica el rediseño o la creación de una nueva institucionalidad en el interior de la cual se apliquen las políticas públicas socio-económicas y urbano-ambientales sustentadas en criterios de universalidad, equidad y sostenibilidad económica, social y ambiental.

\section{Lista de referencias}

Aguilar, Adrián Guillermo (2002), "Las mega-ciudades y las periferias expandidas. Ampliando el concepto en Ciudad de México", Revista EURE, vol. 28, núm. 85, Santiago de Chile. (2004), Introducción, en Procesos metropolitanos y grandes ciudades. Dinámicas recientes en México y otros paises. México, Puecunam, H. Cámara de Diputados, Lix Legislatura, Porrúa.

Aguilar, Adrián Guillermo y Hernández Lozano, Josefina (2012), “Transformación metropolitana y estructura policéntrica en la Ciudad de México. Identificación de subcentros urbanos, 1990-2005”, en Alicia Ziccardi (coord.). Ciudades del 20Io. Entre la sociedad del conocimiento y la desigualdad social. México, PUEC-UnAM.

Álvarez, Lucía y Alicia Ziccardi (20I5), "Las nuevas políticas urbanas y el derecho a la ciudad”, en Carrión, Fernando (coord.), Ciudades de izquierda, Quito, Ecuador, Flacso (en prensa).

Ascher, Francois (2004), Los nuevos principios del urbanismo. El fin de las ciudades no está a la orden del día, Madrid, Alianza Editorial.

Arce, C, Cabrero, E y Ziccardi, A. (coord) (2005), Ciudades del siglo XXI: ¿Competitividad o cooperación?, México, Porrúa, Centro de Investigación y Docencia Económicas (CIDE).

Bodemer, K. Coraggio, J. L. y Ziccardi, A. (1999), The urban social policies at the turn of the century, en Cuaderno de Investigacion. Unión Europea, Ciudad de Montevideo,

Borja, Jordi (I975), Movimientos sociales urbanos, Buenos Aires: Ed. siap. (2005), Las ciudades en la globalización, en Arce, Carlos, Cabrero, Enrique y Ziccardi, Alicia (coord.), Ciudades del siglo XXI: ¿Competitividad o cooperación?, México, Porrúa, Centro de Investigación y Docencia Económicas (CIDE). 
Cardoso, Fernando H (1971), Comentarios sobre el concepto de sobrepoblación relativa y marginalidad, en Revista Latinoamericana de Ciencias Sociales, Santiago: Elas, ICIs.

Castel, Robert (1995), La metamorfosis de la cuestión social. Una crónica del trabajo salariado, Buenos Aires, Paidós.

Castells, Manuel (1972), Proposiciones teóricas para investigación experimental sobre los movimientos sociales urbanos, en Revista Mexicana de Sociología, vol. 34, núm. I, ene.-marzo. (1974), Los movimientos sociales urbanos, México, Siglo XXI. (20I2), La región metropolitana en red como forma urbana en la era de la información: de la descripción a la información, en Alicia Ziccardi (coord.), Ciudades 20Io. Entre la sociedad del conocimiento y la desigualdad social. México, unAm, México.

Ciccolella, Pablo (20II), Revisitando la metrópolis latinoamericana más allá de la reconstrucción, en Revista Iberoamericana de Urbanismo, núm. 8.

Conapo (20I2a), Catálogo Sistema Urbano Nacional 20I2, México, Consejo Nacional de Población. (20I2b), Delimitación de las zonas metropolitanas de México 20Io, México, Consejo Nacional de Población.

Coneval (2010), Informe de Pobreza en México, el pais, los estados y sus municipios 20Io, México, CONEval.

Cuenya, B., Novais, P. y Vainer, C. (comps.) (2012), Grandes Proyectos Urbanos. Miradas criticas sobre la experiencia argentina y brasilena, Buenos Aires, Editorial Café de las Ciudades.

Dematteis, Giuseppe (1998), "Suburbanización y periurbanización. Ciudades anglosajonas y ciudades latinas”, en F. Javier Monclús (ed.), La ciudad dispersa, Barcelona, Centro de Cultura Contemporània de Barcelona.

De Mattos, C. (200I), "Metropolización y suburbanización”, Revista EURE, vol. 27, núm. 80, 5-8, Universidad Católica de Chile.

Duhau, Emilio y Giglia, Angela (2008), Las reglas del desorden: habitar la metrópoli. México, Siglo Xxi Editores, UAM-A.

Duque, Joaquín y Pastrana Ernesto (1972), "La movilización reivindicativa de los sectores populares de Chile (1964-I972)”, en Revista 
Latinoamericana de Ciencias Sociales, núm. 4, Santiago de Chile: FLACSO.

Garza, Gustavo (20I2), Ciudad de México: centralización terciaria intrametropolitana durante la recuperación económica moderada, 2003-2008, en Ziccardi, Alicia (coord.), Ciudades del 2010: entre la sociedad del conocimiento y la desigualdad social, México: UNAM.

Germani, Gino (1967), La ciudad como mecanismo integrador”, en Revista Mexicana de Sociología, vol. 29, núm. 3 (Jul.-Sep.), México, UNAM.

(1973), El concepto de marginalidad, Buenos Aires: Nueva Visión. González, A. y Ziccardi, A. (coord) (2015), Habitabilidad y politicas de vivienda en México. México, Facultad de Economía, Facultad de Arquitectura, Coordinación de Humanidades, PUEC-UnAM. Harvey, David (2013), Ciudades rebeldes. Del derecho de la ciudad a la revolución urbana. Madariaga, Juanmari. Madrid, Akal.

Indovina, Francesco (1990) (2004), "La ciudad difusa", en Lo urbano en 20 autores contemporáneos, Barcelona, Ediciones U PC, pp. 49-59. INEGI (2OIO), Censo de población y vivienda 20Io, México: INEGI.

Kaztman, R. (20II), "Seducidos y abandonados. El aislamiento social de los pobres urbano”. Revista de la CEPAL, 75. Santiago de Chile.

Kosak, Daniel (2009), El neoliberalismo y 'la Ciudad de los Fragmentos', entrevista realizada por Marcelo Corti, Buenos Aires, septiembre.

Lefebvre, H. (1978) (1968), El derecho a la ciudad, Barcelona: Ediciones Península.

(1976) (1972), Espacio y politica: El derecho a la ciudad II, Barcelona, Ediciones Península.

Lewis, Oscar (196I), Antropología de la Pobreza. Cinco Familias, México, FCE.

Lopes de Souza, Marcelo (2004), "Río de Janeiro: una metrópoli fragmentada”, en Adrián Guillermo Aguilar (coord.). Procesos metropolitanos y grandes ciudades. Dinámicas recientes en México y otros paises. México, UnAm, Porrúa. 
Machado Da Silva y Ziccardi, Alicia (198I) "Elementos para una discusión sobre el concepto de movimientos sociales urbanos". Cuadernos del Centro de Estudios Rurais e Urbanos (CERU), No. I3, Sao Paulo: Universidad de Sao Paulo.

NeI-Io, Oriol (I998), "Los confines de la ciudad sin confines. Estructura urbana y límites administrativos en la ciudad difusa”, en F. Javier Monclús (ed.), La ciudad dispersa. Barcelona, Centro de Cultura Contemporànea de Barcelona.

Nivón, Eduardo y Rosas Mantecón, Ana (1994), Oscar Lewis revisitado, en Alteridades 4 (7). Ciudad de México.

Nun, José (1969), Superpoblación relativa, ejército industrial de reserva y masa margina, en Revista Latinoamericana de Sociología, vol V, núm. 2, julio, Buenos Aires.

ONU-Habitat, (S/F), "Urbanización: Mega y metaciudades, ¿las nuevas ciudades-estados?", Un-Habitat.

(S/F), “Tendencias urbanas: corredores urbanos. ¿Será así el futuro?, Un-Habitat.

Pérez Maldonado, Hugo (20I7), La fragmentación socio espacial y la política de vivienda en el ámbito local. La producción de vivienda social en el Municipio de Zumpango, Estado de México 199220I2, tesis de doctorado, Programa de Posgrado en Urbanismo, México: UnAM.

Pipitone, Ugo (2003), 32núm. 27, México: CIDE.

Pírez, Pedro (20I4) La mercantilización de la urbanización. A propósito de los 'conjuntos urbanos' en México, en Estudios Demográficos y Urbanos, vol. 29, núm. 3 (87), México, El Colegio de MéolMEX, pp. 48I-5I2.

puec-unam (20I2), Programa de Ordenación de la zona metropolitana del valle de México (pozmvm) Actualización 20I2. México: GDF, Gobierno del Estado de Hidalgo, Gobierno del Estado de México, Sedesol.

Reygadas y Ziccardi (20Io) México: Tendencias modernizadoras y persistencia de la desigualdad, en Cordera, Rolando (comp.) Presente y Perspectivas. Colección: Historia crítica de las moderniza- 
ciones en México, Fondo de Cultura Económica, Centro de Investigación y Docencia Económicas (FCE/CIDE).

Rubalcava, R. y Scheteingart, M (2012), Ciudades divididas. Desigualdad y segregación social en México, México: Colegio de México.

Sabatini, F. Cáceres Gonzalez y Cerda, J. (200I), "Segregación residencial en las principales ciudades chilenas: tendencias de las tres últimas décadas y psibles cursos de acción”. En, Revista EURE, núm., 82, Santiago de Chile.

Sassen, Saskia (2004), "La ciudad global: introducción a un concepto", en Las múltiples caras de la globalización. Madrid: Editorial B BVVA, pp. 5I-62.

(20II), "La recomposición de las ciudades y las regiones urbanas en la economía global”, en Ciudad y globalización, Quito: OLACCHI, pp. 207-254.

Secretaría de Desarrollo Social (20I2), "La expansión de las ciudades I980-20Io", México, SEDESOL.

Sen, Amartya (200I), La Desigualdad Económica, México: FCE.

Segura, Ramiro (2015), "Desigualdades socio-espaciales en ciudades latinoamericanas: segregación y fragmentación urbanas en un escenario paradojal", en Elizabeth Zenteno y Alejandro Sethman (coords.), Continuidades, rupturas y emergencias. Las desigualdades urbanas en América Latina, México, PUEC-UnAm (en prensa).

Soja, Edward (2004), Seis discursos sobre la postmetrópolis, en Ángel Martín Ramos (ed.), Lo urbano en 20 autores contemporáneos, Barcelona:,Ediciones UPC.

(20IO), Tensiones urbanas: globalización, reestructuración económica y transición postmetropolitana, en Núria Benach y Abel Albet, Edward W. Soja. La perspectiva postmoderna de un geógrafo radical, Barcelona, Icaria, Espacios críticos.

Suárez, Manuel; Ruiz, Naxhelli y Javier Delgado (2012), "Desigualdad, desarrollo humano y la consolidación urbano-regional en México", en Revista EURE (Santiago), vol. 38, núm. II5.

Townsend, Peter (1970), The concept of poverty, London, Heinemann. 
Ziccardi, Alicia (1977), Política de vivienda y movimientos urbanos. El caso de Buenos Aires (I963-I973), Buenos Aires, CEUR-Di Tella. (1983) "Villas Miseria y Favelas, sobre las relaciones del Estado y la organización social en las democracias de los años sesenta”, Revista Mexicana de Sociología, año Xlv, vol. Xlv, núm. I, México, insunam. (1984), "El tercer gobierno peronista y las Villas Miseria de Buenos Aires (1973-1976)", Revista Mexicana de Sociología, año XLVI, vol. Xlvi, núm. 4, octubre/diciembre, México, IIs unam. (1989), De la ecología urbana al poder local, en Revista Mexicana de Sociología, año LI, núm. 1, enero-marzo, 1989. México, IISUNAM.

(2008a), Ciudades latinoamericanas: Procesos de marginalidad y exclusión social, en R. Cordera, P. Ramírez Kuri y A. Ziccardi (coords.), Pobreza, desigualdad y exclusión social en la ciudad del siglo XXI, México, Siglo xxi, IIsunam, pp. 73-9I.

(2008b), Políticas de inclusión social de la Ciudad de México, en C. Barba (comp.), Retos para la superación de la pobreza y la integración económica y social en América Latina, Buenos Aires, CLACSO.

(2008c) (comp.), Procesos de urbanización de la pobreza y nuevas formas de exclusión social. Los retos de las políticas sociales de las ciudades latinoamericanas del siglo XXI, Buenos Aires, CLACso. (20I2) (coord.), Ciudades del 20Io, entre la sociedad del conocimiento y la desigualdad social. México, Programa Universitario de Estudios sobre la Ciudad, unam.

(2013), Desigualdad urbana, espacio público y participación ciudadana, en, T. Cohen (org). Reinvenção da democracia na América Latina, Letra Capital, Rio de Janeiro, pp. 85-Io8. (2015), Cómo viven los mexicanos. Análisis regional de las condiciones de habitabilidad de la vivienda, México, IIJ, Dirección de Fomento Editorial, UnAM. (2018a), Pobreza y desigualdad: retos de la política de vivienda en México (2000-2016) en Midaglia, Carmen, Ordóñez, Gerardo y Valencia, Enrique (coords.), Las Políticas sociales en América La- 
tina en los inicios del siglo XXI: innovaciones, inercias y retrocesos, Buenos Aires, El Colegio de la Frontera Norte, ClaCso, ASDI. (20I8b), Ciudad de México: dos modelos de ciudad y una conflictiva gobernanza local, en Revista Latinoamericana de Investigación Crítica, ańo V, núm. 8, enero-junio. Buenos Aires. (2010) (coord.), Cuaderno de Investigación Trayectorias de Vida. Mujeres dirigentes del comercio popular en el Centro Histórico de la Ciudad de México. México, Programa Universitario de Estudios sobre la Ciudad, unAM. 